\title{
Exploitation of PGPR Endophytic Burkholderia Isolates to Enhance Organic Agriculture
}

\author{
Sandanakirouchenane Aroumougame ${ }^{1, ~}$, Thirumangai Mannan Geetha ${ }^{2}$, Muthu Thangaraju ${ }^{3}$ \\ ${ }^{1}$ Department of Microbiology, School of Life Sciences, Pondicherry University, Puducherry, India \\ ${ }^{2}$ Department of Agricultural Microbiology, Adhiparasakthi Agricultural College, Kalavai, India \\ ${ }^{3}$ Department of Agricultural Microbiology, Tamil Nadu Agricultural University, Coimbatore, India
}

Email address:

sandana03@yahoo.co.in (S. Aroumougame)

${ }^{*}$ Corresponding author

\section{To cite this article:}

Sandanakirouchenane Aroumougame, Thirumangai Mannan Geetha, Muthu Thangaraju. Exploitation of PGPR Endophytic Burkholderia Isolates to Enhance Organic Agriculture. American Journal of BioScience. Vol. 8, No. 3, 2020, pp. 57-64.

doi: 10.11648/j.ajbio.20200803.12

Received: September 18, 2019; Accepted: October 4, 2019; Published: May 28, 2020

\begin{abstract}
Although many bacterial species have been isolated from the rhizosphere of various crop plants, the recent discovery is Burkholderia sp., an endophytic bacterium. In this study, the Burkholderia isolates viz., $\mathrm{RB}_{1}$ (Rice Burkholderia 1), $\mathrm{MB}_{2}$ (Maize Burkholderia 2), $\mathrm{SB}_{3}$ (Sugarcane Burkholderia 3) and $\mathrm{BB}_{4}$ (Black gram Burkholderia 4) were enumerated from the root, stem and leaf samples of four different crops viz., rice, maize, sugarcane and black gram using $\mathrm{N}-\mathrm{free} \mathrm{BAz}$ (Burkholderia Azelaic acid) medium, in which black gram roots were observed higher population. Further, growth promoting activities of the Burkholderia isolates were examined, the maximum production of IAA and GA was noticed on the $\mathrm{BB}_{4}$ as compared to other isolates and the cytokinin production was recorded more in isolates $\mathrm{SB}_{3}$ followed by $\mathrm{BB}_{4}$. $\mathrm{Among}_{\text {mo }}$ the four isolates, maximum amount of salicylate type was noticed in $\mathrm{RB}_{1}$ and catechol type was recorded higher in $\mathrm{BB}_{4}$ which showed that these isolates were capable to produce Siderophore. The ACC deaminase activity of the isolates were exhibited, the $\mathrm{BB}_{4}$ was recorded more followed by $\mathrm{SB}_{3}$. Therefore, the endophytic Burkholderia isolates also the important contributor to the crop growth through secretion of growth promoting substances, production of siderophore and ACC deaminase activities may improve the Agriculture production.
\end{abstract}

Keywords: Burkholderia Isolates, Endophytes, Indole Acetic Acid, Gibberellic Acid, Cytokinin, Siderophore, ACC Deaminase

\section{Introduction}

It has been well established that rhizosphere region forms a conducive environment for various microorganisms and always witnessed with enhanced activity when compared to non-rhizosphere region $[1,2]$. The studies demonstrated the role of different microbes of rhizosphere region in particular plant growth promoting rhizobacteria has been well elucidated. Beneficial rhizobacteria that stimulate plant growth are usually referred to as Plant Growth Promoting Rhizobacteria or PGPR group $[3,4]$ that includes different bacterial species and strains belonging to genera such as Acetobacter, Azospirillum, Azotobacter, Bacillus, Burkholderia, Herbaspirillum and Pseudomonas [5-7].
Several studies have been proposed explaining the potential of PGPR on various agricultural crops which includes phosphorus solublisation [8], growth promotion [9], plant pathogen control [10], micronutrients solubilisation [11], nutrient recycling [11] and so on. Further in order to establish positive interactions with roots of the plants, production of PGPR organism in larger scale has been initiated and following which many different PGPR organisms have been discovered and proposed by scientist.

Among PGPR organisms Burkholderia cepacia (previously known as Pseudomonas) a nutritionally versatile and gram-negative organism was first demonstrated in 1949 by Walter Burkholder of Cornel University. But he proposed it as the phytopathogen responsible for bacterial rot of onions [12] which forms 
endophytic association with the plants. Though it has been introduced as phytopathogen, further studies on the strains confirmed its plant growth promoting properties. From then, interestingly Burkholderia sp. has been isolated from rhizosphere regions as well as different parts of plants. To state few, H. seropedicae and Burkholderia strains found to colonise the roots and shoots of the rice plants grown in JNFB and JMV semi-solid media in high numbers. High population of endophytic bacteria $\left(10^{5}-10^{8}\right)$ were also observed in 25 rice genotypes grown on Philippines, but only in four genotypes was the incidence of endophytic diazotrophs [13]. The same has been reported by [14] with sugarcane. The cluster formed by the diazotrophic species $B$. kururiensis and $B$. tuberum was clearly different from the diazotroph $B$. vietnamiensis which belongs to the " $B$. cepacia complex" [15]. Another diazotrophic bacteria representative of the genus Burkholderia have been isolated from rice plants and sugarcane plants and named as $B$. brasilensis [14]. It also suggested that rice stems are more suitable niches for $\mathrm{N}_{2}$ fixing endophytes than roots because more photosynthates are available to the bacteria [13].

Apart from rice and sugarcane the occurrence of Burkholderia sp. has been reported by many workers in Horticulture crops as well. Tentatively named species of Burkholderia recovered from various parts of banana and pineapple plants as B. tropicalis and B. Brasilensis [16]. Recently analysis of maize, sorghum and coffee plants grown under field conditions revealed the presence of the genus Burkholderia.

Apart from its ubiquitous association with several crops, there are several reports also stated the plant growth promoting activities of Burkholderia sp. to the host plant. Under diverse environmental conditions they are able to communicate and interact with the plants more efficiently than rhizospheric bacteria and significantly impact plant growth by enhancing nutrient uptake by host plants, produce several active compounds, suppresses pathogens by producing antibiotics, siderophores and antifungal compounds [17-21].

With respect to 1-aminocyclopropane-1-carboxylic acid (ACC) deaminase activity of growth of $\mathrm{N}_{2}$ fixing Burkholderia unamae isolates using 1-aminocyclopropane-1carboxylic acid (ACC) as the sole nitrogen source was tested on BAz-medium [22]. They have mechanism to produce the enzyme 1-aminocyclopropane-1-carboxylate (ACC) deaminase. The enzyme is responsible for the cleavage of the plant ethylene precursor, ACC, into ammonia and ketobutyrate [23]. It works on the principle by decreasing ethylene levels in plants which prevents plant growth inhibition.

Thus plants growing with these organisms with ACC deaminase activity will have longer roots and shoots. In addition other vital functions such as seed germination, root hair development, adventitious root formation, nodulation, leaf and fruit abscission, and flower and leaf senescence have been found to be influenced by ethylene [24, 25]. Hence, the organisms will have a positive influence on that too. In our earlier study Burkholderia isolates were collected from the root, stem and leaf samples of four different crops viz., rice, maize, sugarcane and black gram, using $\mathrm{N}$-free $\mathrm{BAz}$ (Burkholderia Azelaic acid) semi solid medium for isolation, screening of Burkholderia isolates viz., $\mathrm{RB}_{1}$ (Rice Burkholderia 1), $\mathrm{MB}_{2}$ (Maize Burkholderia 2), $\mathrm{SB}_{3}$ (Sugarcane Burkholderia 3) and $\mathrm{BB}_{4}$ (Black gram Burkholderia 4) and their nitrogen fixing ability has been observed [26]. The study was also initiated by using them as Bioinoculant. In current study, Burkholderia isolates were enumerated and evaluated on plant growth promoting activities, production of siderophore and ACC deaminase activity.

\section{Materials and Methods}

\subsection{Reference Strains}

The reference strains of Burkholderia sp. viz., Burkholderia vietnamiensis and Burkholderia tropicalis were obtained from Prof. P. Vandamme, Gent University, Belgium and Dr. J. Balandreau, Institute of Research for Development, South Africa respectively.

\subsection{Enumeration of Burkholderia sp. from Different Crop Plants}

The method of enumeration of endophytes described by [27] was adopted for the isolation of Burkholderia from the root, stem and leaves of plant samples collected. The fresh plant samples were carefully separated into stem, roots and leaves. Each part was cut in to sections of 2-3 cm lengths and dried on absorbent towels. One gram of each part was taken and was surface sterilized for 1 min with 70 per cent ethyl alcohol and 1 per cent chloramines-T. The plant parts were washed thoroughly with sterile distilled water thrice to remove the traces of chloramines- $T$ and homogenized in a sterile pestle and mortar in laminar chamber. The homogenized suspension was diluted to $10^{-3}$ and one $\mathrm{ml}$ of the suspension was poured on the plate containing BAz agar medium. The plates were incubated at room temperature for 3 days. The colonies were selected based on the morphological characteristic such as colour, shape, margin, elevation and growth pattern. The isolates were numbered accordingly and thereafter the culture was maintained in respective agar slants. After subsequent sub culturing the isolates were used for further studies.

\subsection{Determination of Indole Acetic Acid Production}

$\mathrm{BAz}$ broth was dispensed in $100 \mathrm{ml}$ quantities in $250 \mathrm{ml}$ flask and sterilized. Freshly filter sterilized solution of $0.2 \%$ L-Tryptophan was added to one set of flask. The media prepared without L-tryptophan was maintained as control [28]. One $\mathrm{ml}$ standard inoculum of Burkholderia isolates were added into each flask and incubated at $37^{\circ} \mathrm{C}$ for 7 days in dark. After 7 days of incubation, the culture was centrifuged at $6000 \mathrm{rpm}$ to remove the bacterial cells. The 
supernatant solution after centrifugation was adjusted to $\mathrm{pH}$ 2.8 with $1 \mathrm{~N} \mathrm{HCl}$. Acidified supernatant of $15 \mathrm{ml}$ volume was taken in $100 \mathrm{ml}$ conical flask and equal volumes of diethyl ether was added to it and incubated in dark for $4 \mathrm{hrs}$. IAA extraction was done at $4^{\circ} \mathrm{C}$ by keeping overnight in a separating funnel using diethyl ether. The organic phase was discarded and the solvent phase was pooled and evaporated to dryness. To the dried residue $2 \mathrm{ml}$ of methanol was added and the IAA present in the methanol extract was determined using the method described by [29]. To $0.5 \mathrm{ml}$ of the above methanol extract $1.5 \mathrm{ml}$ of distilled water and $4 \mathrm{ml}$ of Salpers reagent $\left(1 \mathrm{ml}\right.$ of $0.5 \mathrm{M} \mathrm{FeCl}_{3}$ in 50 $\mathrm{ml}$ of $35 \%$ Perchloric acid) were added and incubated in dark for one hour. The intensity of pink colour was read at $535 \mathrm{~nm}$ in a double beam spectrophotometer. From the standard curve prepared with known concentration of IAA, the quantity in the culture filtrate was determined and expressed as $\mu \mathrm{g} \mathrm{ml}^{-1}$.

\subsection{Determination of Gibberellic Acid Production}

\subsubsection{Extraction of Gibberellins}

One $\mathrm{ml}$ of culture was inoculated in the BAz broth and incubated for 7 days at room temperature. The cultures were centrifuged for 10 minutes at $10,000 \mathrm{rpm}$ and the supernatant was taken. The cell pellet was re-extracted with phosphate buffer $(\mathrm{pH}$ 8.0) and again centrifuged. Both supernatants were collected and pooled, acidified to $\mathrm{pH} 2.0$ with $5 \mathrm{~N}$ hydrochloric acid and extracted with equal volumes of ethyl acetate twice [30]. The ethyl acetate phase was evaporated at $32^{\circ} \mathrm{C}$ and the residue was redissolved in $2 \mathrm{ml}$ of distilled water containing 0.05 per cent of Tween 80 .

\subsubsection{Spectrophotometric Estimation of Gibberellins ( $\left.\mathrm{GA}_{3}\right)$}

Two $\mathrm{ml}$ of zinc acetate solution was added to the dissolved residue. After two min, two $\mathrm{ml}$ of potassium ferro cyanide solution was added and the mixture was centrifuged at $10,000 \mathrm{rpm}$ for $10 \mathrm{~min}$. Five $\mathrm{ml}$ of supernatant was added to $5 \mathrm{ml}$ of 30 per cent hydrochloric acid and the mixture was incubated at $20^{\circ} \mathrm{C}$ for $75 \mathrm{~min}$. The blank was prepared with 5 per cent hydrochloric acid. The absorbance was measured at $254 \mathrm{~nm}$ in spectrophotometer. From the standard gibberellic acid solution, the amount of GA produced by the culture was calculated and expressed as $\mu \mathrm{g} \mathrm{ml}^{-1}$.

\subsection{Estimation of Cytokinin}

\subsubsection{Extraction from Culture Filtrates}

The organisms were grown in BAz media until good growth and centrifuged at $10,000 \mathrm{rpm}$ for 10 minutes. The cell free supernatants were collected and adjusted to $\mathrm{pH} 2.8$ with $1 \mathrm{~N} \mathrm{HCl}$. To the culture filtrate in separating funnel equal volume of cold $\left(4^{\circ} \mathrm{C}\right)$ diethyl ether was added, mixed and allowed to stand for 4 hours at $4^{\circ} \mathrm{C}$ with intermittent shaking. The aqueous phase was separated from the organic phase and evaporated to dryness in the dark. The residue was dissolved in $2.0 \mathrm{ml}$ of absolute alcohol and used for bioassay.

\subsubsection{Radish Cotyledon Assay}

Radish seeds were surface sterilized with $0.5 \%$ sodium hypochlorite solution and after rinsing with sterile water, it was allowed to germinate on blotter paper in darkness at $25-26^{\circ} \mathrm{C}$ for three days. Cotyledons of uniform weight were selected and placed on filter paper in $9 \mathrm{~cm}$ petriplates. Ten $\mathrm{ml}$ of $2 \mathrm{mM}$ potassium phosphate buffer of $\mathrm{pH} 5.9$ followed by one $\mathrm{ml}$ of cell free culture extract prepared earlier were added to petriplates. Similar set of experiments were conducted with various concentrations of Benzyl amino purine viz., 2, 4, 6, 8 and $10 \mu \mathrm{g} \mathrm{ml}^{-1}$ instead of culture extract. Cotyledons were incubated under continuous weak fluorescent light for three days at $24^{\circ} \mathrm{C}$. The weights of the cotyledons were recorded after drying with blotting paper and a dosage response curve was drawn.

\subsection{Determination of Siderophore Production}

Siderophore production was estimated by the method described by [31]. BAz broth was prepared and dispensed in $100 \mathrm{ml}$ quantities in $250 \mathrm{ml}$ flasks and sterilized. One $\mathrm{ml}$ of Burkholderia isolates was added into above medium and incubated at $37^{\circ} \mathrm{C}$ for 7 days. After incubation, the broth culture was centrifuged at $10,000 \mathrm{rpm}$ for 10 minutes. Twenty $\mathrm{ml}$ of culture supernatant was taken and the $\mathrm{pH}$ was adjusted to 3.0. To this $20 \mathrm{ml}$ of ethyl acetate was added and extraction was done twice. The solvent was evaporated and then residue was dissolved using distilled water. It was used as assay solution for the estimation of catechol type and salicylic type of siderophore.

\subsubsection{Salicylate Type of Siderophore}

Five $\mathrm{ml}$ of the assay solution was added with $5 \mathrm{ml}$ of Hathway reagent $\left(1 \mathrm{ml}\right.$ of $0.1 \mathrm{M} \mathrm{FeCl}_{3}$ and $1 \mathrm{ml}$ of $0.1 \mathrm{~N}$ $\mathrm{HCl}$ was added to $100 \mathrm{ml}$ distilled water and to this $1 \mathrm{ml}$ of $0.1 \mathrm{M}$ potassium ferrocyanide was added) and absorbance was determined at $560 \mathrm{~nm}$ with sodium salicylate as standard for the estimation of salicylic type of siderophore.

\subsubsection{Catechol Type of Siderophore}

For the measurement of catechol type siderophore, $5 \mathrm{ml}$ of Hathway reagent was added with $5 \mathrm{ml}$ of assay solution and the absorbance was determined at $700 \mathrm{~nm}$ with 2,3, di hydroxy benzoic acid as standard.

\subsection{Determination of ACC Deaminase (1-Amino- Cyclopropane-1-Carboxylic Acid) Activity}

ACC deaminase activity of the cell was determined as per method described by [32]. One $\mathrm{ml}$ of the bacterial culture was added to $50 \mathrm{ml}$ sterile PAF medium in a $250 \mathrm{ml}$ flask. The flask and its contents were incubated in a shaking water bath $(200 \mathrm{rpm})$ at a temperature between 25 and $30^{\circ} \mathrm{C}$ After $24 \mathrm{hr}, 1 \mathrm{ml}$ aliquot was removed from the growing culture, transferred to $50 \mathrm{ml}$ of sterile PAF medium in a 250 $\mathrm{ml}$ conical flask and incubated at $200 \mathrm{rpm}$ in a shaking water bath for $24 \mathrm{hr}$, at the same temperature as the first incubation (Following these incubation, the population of 
Burkholderia and other bacteria were enriched and the number of fungi in the culture was reduced). One $\mathrm{ml}$ aliquot was removed from the second culture and transferred to 250 $\mathrm{ml}$ flask containing $50 \mathrm{ml}$ sterile DF minimal salt medium in a $250 \mathrm{ml}$ flask containing $3.0 \mathrm{mM}$ ACC deaminase. The culture was placed in a shaking water bath at $200 \mathrm{rpm}$ and grown for $24 \mathrm{hr}$ at $25-30^{\circ} \mathrm{C}$. The bacteria were harvested by centrifugation at $8000 \mathrm{~g}$ for 10 minutes at $4^{\circ} \mathrm{C}$. The supernatant was removed and the cells were washed by suspending the cell pellet in $5 \mathrm{ml} 0.1 \mathrm{M}$ Tris- $\mathrm{HCl}, \mathrm{pH} 7.6$ and assayed for ACC deaminase activity by Spectrophotometer at $540 \mathrm{~nm}$.

\subsection{Statistical Analysis}

All experiments were conducted in triplicates and mean and standard deviation were determined. Data sets were subjected to analysis of variance (ANOVA) on Windows Excel.

\section{Results}

\subsection{Enumeration of Burkholderia sp. from Different Crops}

The population of Burkholderia was enumerated from different parts of rice, maize, sugarcane and black gram and the data were presented in Table 1. The population was comparatively more in the root samples than stem and leaf of the crops studied. Black gram roots known to harbour more number of the endophyte (30 CFU g ${ }^{-1}$ tissue) followed by maize. The colonies of Burkholderia isolates were grown on BAz (Burkholderia Azeleic acid) medium were shown in Figure 1.

Table 1. Population of Burkholderia sp. in different parts of crop plants.

\begin{tabular}{llll}
\hline \multirow{2}{*}{ Crops } & \multicolumn{3}{l}{ Population (CFU x 10 $\mathbf{~ g}^{-1}$ tissue) } \\
\cline { 2 - 4 } & Root & Stem & Leaf \\
\hline Rice & 12.5 & 8 & 1.5 \\
Maize & 25 & 9.5 & 2.5 \\
Sugarcane & 3.5 & 2.5 & 0 \\
Black gram & 30 & 19.5 & 6.5 \\
\hline
\end{tabular}

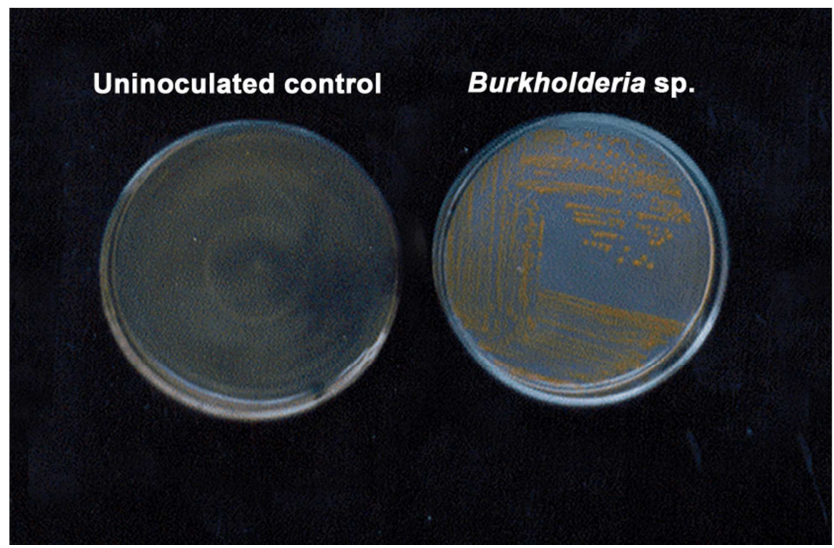

Figure 1. Growth of Burkholderia isolates on BAz agar medium.

\subsection{Production of IAA, GA and Cytokinin by Burkholderia Isolates}

We were presenting detailed investigation of Burkholderia isolates of quantity of IAA produced without tryptophan varied between 1.80 and $3.61 \mu \mathrm{g} \mathrm{ml}{ }^{-1}$. Among the isolates, $\mathrm{BB}_{4}$ produced higher quantity of IAA (3.61), which was followed by $B$. vietnamiensis (3.03), $\mathrm{RB}_{1}(2.86), \mathrm{SB}_{3}$ (2.52) and $\mathrm{MB}_{2}$ (2.35). Similarly, quantity of IAA produced with tryptophan varied from 2.77 to $5.06 \mu \mathrm{g} \mathrm{ml}^{-1}$. Among the isolates, $\mathrm{BB}_{4}$ produced higher quantity of IAA (5.06), followed by $B$. vietnamiensis (4.03), $\mathrm{RB}_{1}$ (3.89), Burkholderia tropicalis (3.45), $\mathrm{SB}_{3}$ (3.36) and $\mathrm{MB}_{2}$ (2.07), the results were showed in Figure 2. Quantity of GA produced varied between 2.39 and $3.82 \mu \mathrm{g} \mathrm{ml}^{-1}$. Among the isolates, $\mathrm{BB}_{4}$ recorded higher quantity of GA (3.82), which was followed by Burkholderia tropicalis (3.69), $\mathrm{RB}_{1}$ (3.11), $\mathrm{MB}_{2}$ (2.76) and the lowest value was recorded in $B$. vietnamiensis (2.39), the results were shown in Figure 3. Cytokinin production was tested by measuring the weight increase of radish cotyledon due to culture extract of Burkholderia as compared to control. Among the isolates, Burkholderia tropicalis $\left(0.463 \mathrm{~g} \mathrm{~g}^{-1}\right)$ recorded maximum increase in weight of radish cotyledon followed by $\mathrm{SB}_{3}$ (0.388), $\mathrm{BB}_{4}(0.357)$, B.v (0.327) and $\mathrm{RB}_{1}(0.309)$ respectively. The lowest weight was recorded in $\mathrm{MB}_{2}$ (Table 2).

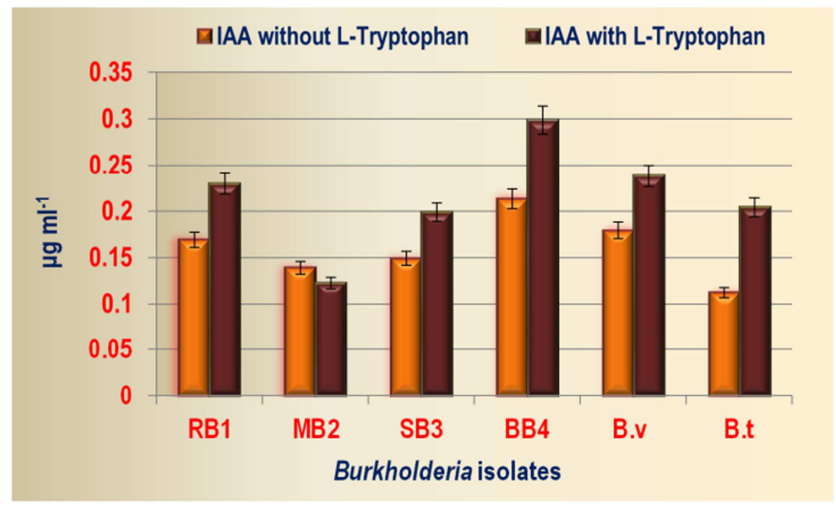

Figure 2. Indole Acetic Acid (IAA) produced by Burkholderia isolates by using BAz medium.

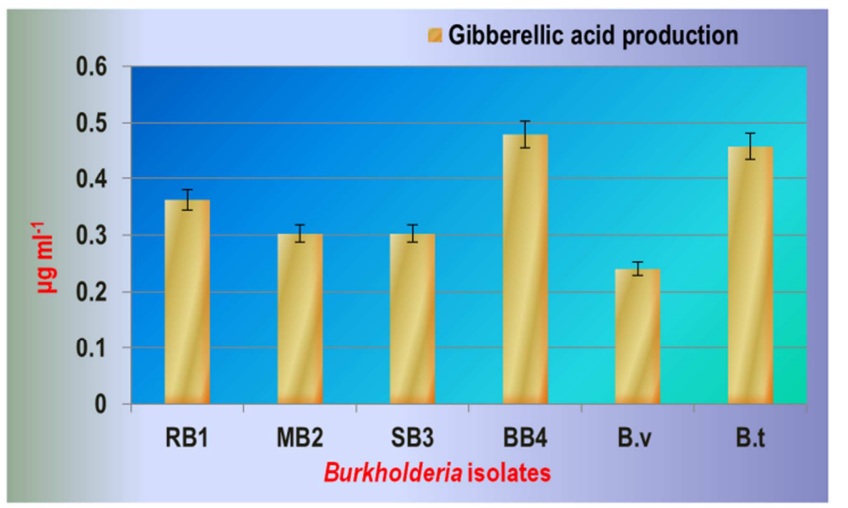

Figure 3. Production of Gibberellic Acid (GA) by Burkholderia isolates grown on BAz medium. 
Table 2. Production of Cytokinin by Burkholderia isolates grown on BAz medium.

\begin{tabular}{llll}
\hline $\begin{array}{l}\text { Burkholderia } \\
\text { isolates }\end{array}$ & $\begin{array}{l}\text { Cytokinin }\left(\mathbf{m g ~}^{\mathbf{- 1}}\right) \\
\text { Weight of radish cotyledons before } \\
\text { adding culture filtrate }(\mathbf{g})\end{array}$ & $\begin{array}{l}\text { Weight of radish cotyledons after } \\
\text { incubating in culture filtrate }(\mathbf{g})\end{array}$ & $\begin{array}{l}\text { Average weight of radish cotyledons } \\
(\mathbf{g})\end{array}$ \\
\hline $\mathrm{RB}_{1}$ & 0.102 & 0.411 & 0.309 \\
$\mathrm{MB}_{2}$ & 0.104 & 0.401 & 0.297 \\
$\mathrm{SB}_{3}$ & 0.104 & 0.492 & 0.388 \\
$\mathrm{BB}_{4}$ & 0.102 & 0.459 & 0.357 \\
$\mathrm{~B}$. vietnamiensis* & 0.098 & 0.425 & 0.327 \\
B. tropicalis* & 0.106 & 0.569 & 0.463 \\
Control & 0.108 & 0.299 & 0.191 \\
$\mathrm{SEd}$ & & & 0.014 \\
$\mathrm{CD}(5 \%)$ & & 0.013 \\
\hline
\end{tabular}

(* - Reference strains)

\subsection{Production of Siderophore by Burkholderia Isolates}

Siderophore production was recorded in all the isolates and in reference strains as well. The higher siderophore (Salicylate type) production was recorded in Burkholderia tropicalis (2.39 $\mu$ moles $\mathrm{ml}^{-1}$ ), which was followed by $B$. vietnamiensis (2.30), $\mathrm{RB}_{1}$ (2.23), $\mathrm{BB}_{4}(2.22)$ and $\mathrm{SB}_{3}$ (2.20). The lowest siderophore production was recorded in $\mathrm{MB}_{2}$ (1.74). Similarly, in the case of catechol type siderophore production, the maximum value was recorded in $\mathrm{BB}_{4}\left(1.72 \mu\right.$ moles $\left.\mathrm{ml}^{-1}\right)$ followed by Burkholderia tropicalis (1.66), $\mathrm{MB}_{2}$ (1.61), $\mathrm{RB}_{1}$ (1.53), $\mathrm{SB}_{3}$ (1.47) and the lowest value was recorded in B. vietnamiensis (1.45), both the results were presented in Figure 4.

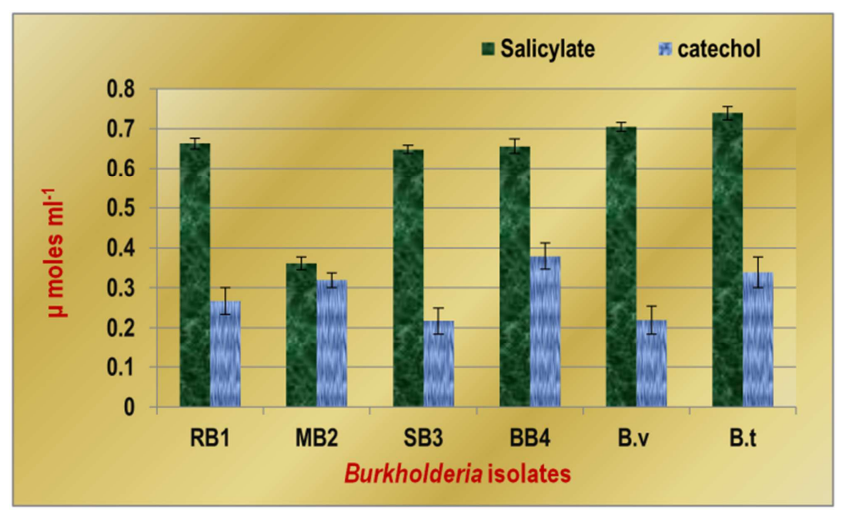

Figure 4. Siderophore production of Burkholderia isolates.

\subsection{Production of ACC (1-Aminocyclopropane 1- Carboxylic Acid) Deaminase by Burkholderia Isolates}

ACC deaminase activity was recorded in all the isolates and in reference strains. The highest value was recorded in $B$. vietnamiensis (1.32 nmoles $\mathrm{h}^{-1}$ ) followed by $\mathrm{BB}_{4}, \mathrm{SB}_{3}$, Burkholderia tropicalis and $\mathrm{MB}_{2}$. The lowest value was recorded in $\mathrm{RB}_{1}$. The results were presented in Table 3 .

Table 3. ACC deaminase activity of Burkholderia isolates.

\begin{tabular}{ll}
\hline Burkholderia isolates & $\begin{array}{l}\text { ACC deaminase activity (n moles of } \boldsymbol{\alpha} \text { - } \\
\text { Ketobutyrate } \mathbf{~ m}^{-1} \mathbf{h}^{-\mathbf{1}} \text { ) }\end{array}$ \\
\hline $\mathrm{RB}_{1}$ & 0.44 \\
$\mathrm{MB}_{2}$ & 0.58 \\
$\mathrm{SB}_{3}$ & 0.67 \\
$\mathrm{BB}$ & 1.18 \\
B. vietnamiensis* & 1.32 \\
\hline
\end{tabular}

\begin{tabular}{ll}
\hline Burkholderia isolates & $\begin{array}{l}\text { ACC deaminase activity (n moles of } \boldsymbol{\alpha} \text { - } \\
\text { Ketobutyrate } \mathbf{~ m}^{-\mathbf{1}} \mathbf{h}^{-\mathbf{1}} \text { ) }\end{array}$ \\
\hline B. tropicalis* & 0.64 \\
SEd & 0.03 \\
CD $(5 \%)$ & 0.07 \\
\hline
\end{tabular}

(* - Reference strains)

\section{Discussion}

The present study showed that the population of Burkholderia was comparatively more in the root samples than stem and leaf of the crops studied. Similar results were observed by [33] who reported more number of nitrogen fixing Burkholderia sp. in root tissues of maize than shoot. In another study Burkholderia represented 2-7 per cent of culturable bacteria isolated from soil and 17-25 per cent culturable bacteria from roots of sugarcane, indicating the close association between Burkholderia sp. and sugarcane root in the presence of other indigenous microorganisms [34]. Similarly more number of these bacteria was observed in the roots of rice as reported by [35]. Thus, it is clearly shown that Burkholderia are root endophytic organisms in various crop plants. As reports suggest their occurrence, various reports of effects of rhizophere organisms in crop improvement have been published.

Microorganisms in the rhizosphere of crop plants produce several phytohormones as plant growth regulating substances. Auxin is a key hormone for various aspects of plant growth and development, thus its synthesis by bacteria is probably one of the reasons for the alterations observed in plant metabolism. The presence of Indole acetic acid (IAA) in the methanolic extract from growth media of $B$. brasilense and Herbaspirillum were suggested by [36]. The present study showed that Burkholderia isolate $\mathrm{BB}_{4}$ recorded higher production of IAA when compared to other isolates. Similar results were reported by [37] in Stenotrophomonas maltophilia for IAA production whereas Pseudomonas putida for GA (Gibberellic acid) and Cytokinin production. In present experiment, the isolates showed the IAA and GA production in significantly higher quantity. Similar to the present study reports suggesting microbial production of IAA and GA. Besides auxin production, Pseudomonas fluorescence was also found to produce gibberellic acid substance [38, 39]. It was observed that extremely high amount of IAA production by Azospirillum [40]. However, 
the amount of IAA produced varies with the species and the condition of cultivation [41]. The strains of Bacillus thuringiensis C110, Pseudomonas fluorescens Th98 and Pseudomonas poae Th75 also proved to be effective PGPR inoculants [42]. Pseudomonas Spp. for K8 and Azotobacter Spp. for K37 isolates were produced higher amount of Gibberellic acid also identified with effect of $\mathrm{pH}$, incubation temperature, carbon and nitrogen sources [43]. The endophytic Burkholderia isolates were produced by IAA and GA from cultivated sugarcane crops is used as growth regulator which may potent native for development of biofertilizer production [44].

Production of this type of plant growth regulators (IAA and cytokinin) have been earlier observed in Rhizobium [45], Azotobacter [46], Azospirillum [47, 28] and in phosphobacteria [48]. The Burkholderia isolates tested, produced varied quantities of IAA and cytokinins and it supported the findings of $[49,50]$. They observed the auxin and cytokinin production by many root colonizing bacteria including Pseudomonas sp. The present study of raddish cotyledon bioassay revealed the production of cytokinin by Burkholderia. The amount of cytokinin produced varied among isolates. The reference strain B. tropicalis and the isolates $\mathrm{BB}_{4}$ and $\mathrm{SB}_{3}$ produced high amounts of cytokinin. The use of plant growth promoting rhizobacteria is an eco friendly approach to increase the crop growth to enhance the sustainable Agriculture [51].

Siderophore are relatively low molecular weight $(<1500$ $\mathrm{Kda})$ compounds. There are almost 500 compounds identified as siderophores. They can be divided into hydroxmate, catecholate, salicylate and hydroxy carboxylic acid type [52]. Burkholderia cepacia has been reported to produce four different types of siderophores viz., pyochelin, salicylic acid (SA), cepabactin and ornibactins [53]. More recently, $B$. cepacia strains have also been reported to produce linear hydroxamate or hydroxycarboxylate siderophore termed as ornibactins [54]. Previously, catechol and salicylate type siderophores have been noticed in Azospirillum [55]. In the present experiment, Burkholderia isolates from different crops recorded $2.39 \mu$ moles $\mathrm{ml}^{-1}$ of salicylate type of siderophore and $1.72 \mu$ moles $\mathrm{ml}^{-1}$ of catechol type of siderophore under ion limiting condition, which is in accordance with the findings of [56]. The $B$. cepacia isolates which produce only ornibactins are more related to $B$. vietnamiensis and the production of siderophores may be used to discriminate between these two species [57] in a study suggested that clinical isolates of $B$. cepacia could be differentiated from rhizosphere isolates by their production of pyochelin and salicylic acid. Some of the newly isolated endophytic ACC deaminase strains were produced IAA, Siderophore production, phosphate solubilization activity, optimal growth temperature, salt tolerance and antibiotic sensitivity [58]. Thus, the isolate has been proven to be a versatile PGPR organism.

Moreover, a bacterium may utilize different traits at various times during the life cycle of the plant. PGPR may lower the plant ethylene concentration during seed germination thereby decreasing the ethylene inhibition of seedlings root length [59]. Once the seedling has depleted the resources that are contained within the seed, the same PGPR may help to provide the plant with iron and phosphorus from the soil. For many plants, a burst of ethylene is required to break seed dormancy [60]. But, following germination, a sustained high level of ethylene would inhibit root elongation. PGPR that contain the enzyme ACC deaminase, when bound to the seed coat of a developing seedling act as a mechanism for ensuring that the ethylene level does not become elevated to the point where initial root growth is impaired. Growth of $\mathrm{N}_{2}$ fixing Burkholderia isolates using 1-aminocyclopropne-1carboxylic acid (ACC) as the sole nitrogen source was tested on BAz-ACC medium [22]. In the present study, the ACC enzyme of $1.32 \mathrm{n}$ moles $\mathrm{h}^{-1}$ was produced by $B$. vietnamiensis and followed by local isolate $\mathrm{BB}_{4}\left(1.18 \mathrm{n}\right.$ moles $\left.\mathrm{h}^{-1}\right)$. ACC deaminase has an ability to facilitate plant growth to a much greater extent with plants that are ethylene sensitive such as canola, pepper and tomato, and their activity is useful in Agricultural and Horticultural settings as well as other environmental cleanup [32]. Acc deaminase activity was noticed in Bacillus subtilis as bacterial endophytes [61].

\section{Conclusion}

The present study depicted that the significant PGPR activities of Burkholderia isolates has clearly proven from the results viz., Siderophore production, significant production of growth promoting substances and ACC deaminase activity. Hence the study, putforth Burkholderia isolates as a potential PGPR organism for crop plants and they can be efficiently utilized for crop production. However, further studies on the isolate regarding method of application will help in reaching the technology to field level.

\section{Acknowledgements}

We are thankful to Department of Microbiology, Pondicherry University, Puducherry and Department of Agricultural Microbiology, Tamil Nadu Agricultural University, Coimbatore for providing the facilities to carry out this research work successfully.

\section{References}

[1] Hiltner, L. Iiber neuere Erfahrungen und unter besonderer Berucksichtingung der Grundunging und Brache. Arb. Dtsch. Landw. Ges, 1904, 98; 59-78.

[2] Smalla, K., Sessitsch, A., and Hartmann, A. The rhizosphere: soil compartment influenced by the root. Fed. Eur. Microbiol. Soc, 2006, 56; 165-172.

[3] Davison, J. Plant beneficial bacteria. Biotechnol, 1988, 6; 282286.

[4] Kloepper, J. W., Lifshitz, R., and Zablotowicz, R. M. Freeliving bacterial inocula for enhancing crop productivity. Trends Sci, 1989, 1; 60-64. 
[5] Weller, D. M., and Thomashow, L. S. Current challenges in introducing beneficial microorganisms into the rhizosphere. In: Molecular Ecology of Rhizosphere Microorganisms (eds.) F. Dowling, D. N. and B. Boesten, VCH Verlagsgesellschaft mbH, Weinheim, Germany, 1994, pp. 10-18.

[6] Glick, B. R. The enhancement of free-living bacteria. Can. J. Microbiol, 1995, 41; 109-117.

[7] Probanza, A., Lucas, J. A., Acero, N., and Gutierrez-Manero, F. J. The influence of native bacteria on European alder (Alnus glutinosa (L.) Gaertn.) growth. Characterization of growth promoting and growth inhibiting bacterial strains. Plant Soil, 1996,$182 ; 59-66$.

[8] Suresh, A., Pallavi, P., Srinivas, P., Praveen Kumar, V., Jeevan Chandra, S., R et al. Plant growth promoting activities of fluorescent pseudomonads associated with some crop plants. Afr. J. Microbiol. Res, 2010, 4 (14); 1491-1494.

[9] Bernard Glick, R. Bacteria with ACC deaminase can promote plant growth and help to feed the world. Microbiol. Res, 2014, $169 ; 30-39$.

[10] Sang Hye Jia, Mayank Anand Gururanib, and Se-Chul, C. Isolation and characterization of plant growth promoting endophytic diazotrophic bacteria from Korean rice cultivars. Microbiol. Res, 2014, 169; 83-98.

[11] Premachandra, D., Hudek, L., and Brau, L. Bacterial Modes of Action for Enhancing of Plant Growth. J. Biotech. Biomater, 2016, 6; 3 .

[12] Burkholder, W. Sour skin, a bacterial rot of onion bulbs. Phytopathol, 1950, 40; 115-118.

[13] Barraquio, W. L., L. Sevilla and J. K. Ladha. Isolation of endophytic diazotrophic bacteria from wetland rice. Plant Soil, 1997, 194; 15-24.

[14] Baldani, J. I., L. Caruso, V. L. D Baldani, S. R. Goi and J. Dobereiner. Recent advances in BNF with non-legume plants. Soil. Biol. Biochem, 1997, 29; 911-922.

[15] Vandamme, P., Henry, D., Coenye, T., Nzula, S., Vancanneyt, M., L. et al. Burkholderia anthina sp. nov. and Burkholderia pyrrocinia, two additional Burkholderia cepacia complex bacteria, may confound test results of new molecular diagnostic tools. FEMS Immunol. Med. Microbiol, 2002, 33; 143-149.

[16] Estrada., De-Los-Santos, E., R. Bustillos-Cristales and J. Caballero-Mellado. Burkholderia, a genus rich in plantassociated nitrogen fixers with wide environmental and geographic distribution. Appl. Environ. Microbiol, 2001, 67; 2790-2798.

[17] Arora, N. K., Kang, S. C., and Maheshwari, D. K. Isolation of siderophore-producing strains of Rhizobium meliloti and their biocontrol potential against Marcrophomina phaseolina that causes charcoal rot of groundnut. Curr. Sci, 2001, 81; 673-7.

[18] Persello-Cartieaux, F., Nussaume, L., and Robaglia, C. Tales from the underground: molecular plant-rhizobacteria interactions. Plant Cell Environ, 2003, 26; 189-199.

[19] Kuklinsky-Sobral, J., Araujo, W. L., Mendes, R., Geraldi, I. O., Pizzirani-Kleiner, A. A., A. et al. Isolation and characterization of soybean-associated bacteria and their potential for plant growth promotion. Envirion. Microbiol, 2004, 6; 1244-51.

[20] Frey-Klett, P., Chavatte, M., Clausse, M. L., Courrier, S., Roux, C. L., R. et al. Ecto-mycorrhizal symbiosis affects functional diversity of rhizosphere fluorescent pseudomonads. New Phytol, 2005, 165; 317-28.

[21] Hameeda, B., Rupela, O. P., Reddy, G., and Satyavani, K. Application of plant growth promoting bacteria associated with composts and macro fauna for growth promotion of pearl millet (Pennisetum glaucum L.). Biol. Fertil. Soils, 2006, 43; 221-227.

[22] Caballero-Mellado, J., L. Martinez-Aguilar, G. ParedesValdez and P. Estrada de- lost Santos. Burkholderia unamae sp. nov., a $\mathrm{N}_{2}$ fixing rhizospheric and endophytic species. Int. J. Syst. Environ. Microbiol, 2004, 10; 1-12.

[23] Honma, M., and Shimomura, T. Metabolism of 1aminocyclopropane-1-carboxylic acid. Agric. Biol. Chem, 1978, 42; 341-346.

[24] Bakshi, A., Shemansky J. M., Chang, C., and Binder, B. M. History of research on the plant hormone ethylene. J. Plant Growth Regul, 2015, 34; 809-827.

[25] Shrivastava, P., and Kumar, R. Soil salinity: a serious environmental issue and plant growth promoting bacteria as one of the tools for its alleviation. Saudi J. Biol. Sci, 2015, 22; $123-131$.

[26] Sandanakirouchenane, A., Ekramul Haque, and Geetha, T. Recent Studies on $\mathrm{N}_{2}$ Fixing Burkholderia Isolates as a Biofertilizer for the Sustainable Agriculture. Int. J. Curr. Microbiol. App. Sci, 2017, 6 (11); 2780-2796.

[27] Hallmann, J., Quadt-Hallmann, A., Mahafee, W. F., and Kloepper, J. W. Bacterial endophytes in agricultural crops. Can. J. Microbiol, 1997, 43; 895-914.

[28] Tien, T. M., M. H. Gasking and D. H. Hubbel. Plant growth substances produced by $A$. brasilense and their effect on the growth of pearl millet (Pennisetum americanum L.). Appl. Environ. Microbiol, 1979, 37; 1016-1024.

[29] Gorden, S. A., and Paleg, L. G. Quantitative measurements of indole acetic acid. Physiol. Pl, 1957, 4; 24-27.

[30] Zeigler, R., Powell, L., and Thurston, H. Gibberellin $\mathrm{A}_{4}$ Production by Sphaceloma manihoticola, Causal Agent of Cassava Super Elongation Disease. Physio. Biochem, 1980, 70; 589-593.

[31] Reeves, M. O., Neilands, P. L., and Ballows, A. Absorption of siderophore activity Legionella sp. in iron deficient media. $J$. Bacteriol, 1983, 154; 324-329.

[32] Penrose, D. M. and B. R. Glick. Methods for isolating and characterizing ACC deaminase-containing plant growthpromoting rhizobacteria. Physiol. $\mathrm{Pl}, 2003,118 ; 10-15$.

[33] Estrada, P., P. Mavingui, B. Cournoyer, F. Fontaine, J. Balandreau,. C. et al. Nitrogen fixing endophytic Burkholderia sp. associated with maize plants cultivated in Mexico. Can. J. Microbiol, 2002, 48; 285-294.

[34] Vogel, J. L, Balandreau, J., Van Antwerpen, T., Dana, P., and Cadet, P. Isolation and characterization of sugarcane rhizobacteria and their effect on nematodes. Proc. S. Afr. Sug. Technol. Ass, 2002, 76; 305-309. 
[35] Tran Van, V., P. Mavingui, O. berge, J. Balandreau and T. Heulin. Promotion de croissance du riz inocule par une bacterie flxatrice d'azote, Burkholderia vietnamiensis, isolee d'un sol sulfate acide duviet-nam. Agronomic, 2002, 14; 697707.

[36] Neto, R., Malavolta, J. V. A., and Vicot, O. Suma Phytopatologica, 1986, 12; 16.

[37] Tisha, P., and Meenu, S. Biosynthesis of phytohormones from novel rhizobacterial isolates and their in vitro plant growthpromoting efficacy. J. Pl. Interac, 2017, 12 (1); 480-487.

[38] Nita, A. Z. The activity of metabolic products of microorganisms on higher plants. Paper presented at the VIII. Intern. Congr. Soil. Sci. Commission III. Bucharest, 1964, p. 106-107.

[39] Eklund, E. Secondary effects of some pseudomonads in the rhizoplane of peatgrown cucumber plants. Acta. Agr. Second Supple, 1970, 17; 1-57.

[40] Jain, D. K., and Patriquin, D. G. Characterization of a substance produced by a Azospirillum which causes branching of wheat root hair. Can. J. Microbiol, 1985, 31; 206-210.

[41] Esparza, M. A., Villa-Gonzalez, R., and Caballero-Mellado, J. Acetylene reduction and indoleacetic acid production by Azospirillum isolates from cactaceous plants. Plant Soil, 1988, 106; 91-95.

[42] Eman, A. A., Enas, A. H., El Tobgy, K. M. K., and Ramadan, E. M. Evaluation of rhizobacteria of some medicinal plants for plant growth promotion and biological control. Ann. Agri. Sci, 2014, 59 (2); 273-280.

[43] Sagar A. Desai, Isolation and characterization of gibberellic acid (GA3) producing rhizobacteria from sugarcane roots. Biosci. Discovery, 2017, 8 (3); 488-494.

[44] Arthee, R., and Marimuthu, P. Studies on Endophytic Burkholderia $\mathrm{Sp}$. from sugarcane and its screening for Plant Growth Promoting potential. J. Exp. Biol. Agri. Sci, 2017, 5 (2); 242-257.

[45] Shamakharora, N. M. Alfalfa root hair deformation caused by growth substances and Rhizobium meliloti culture fluid extracts. Microbiology. 1979, 48; 276-279.

[46] Barea, J. M., and Brown, M. E. Effects on plant growth produced by Azotobacter paspali related to synthesis of plant growth regulating substances. J. Appl. Bacteriol, 1974, 37 (4); 583-93.

[47] Reynders, L., and Vlassak, K. Conversion of tryptophan to indole acetic acid by Azospirillum brasilense. Soil. Biol. Biochem, 1979, 11; 547-548.

[48] Azcon, G., Agullar, C., and Barea, J. M. Effects of interactions between different culture fractions of phosphobacteria and
Rhizobium on mycorrhizal infection, growth and nodulation of Medicago sativa. Can. J. Microbiol, 1978, 24; 520-524.

[49] Brown, M. E. Plant growth substances produced by microorganisms of soil and rhizosphere. J. Appl. Bacteriol, 1972,$68 ; 1377-1383$.

[50] Mordukhova, E. A., Skvortsova, N. P., Kochetkov, V. V., Dubeikovsky, A. N., and Boronin, A. M. Indole-3-acetic acid, a phytohormone synthesized by the rhizosphere bacteria of the Pseudomonas genus. Mikrobiologia, 1991, 60; 494-500.

[51] Govind, G., Shailendra, S. P., Narendra Kumar, A., Sunil Kumar, S., and Vinod Singh. Plant Growth Promoting Rhizobacteria (PGPR): Current and Future Prospects for Development of Sustainable Agriculture. Microbiol. Biochem. Technol, 2015, 7 (2); 96-102.

[52] Boukhalfa, H., and Crumbliss, A. L. Chemical aspects of siderophore in iron transport. Biometals, 2002, 15; 325-339.

[53] Darling, P., Chan, M., Cox, A. D., and Sokol, P. A. Siderophore production by cystic fibrosis isolates of Burkholderia cepacia. Infect Immun, 1998, 66; 874-877.

[54] Stephan, H., Freund, S., Beck, W., Jung, G., Meyer, J. M., W. et al. Ornibactins-a few family of siderophores from Pseudomonas. Biometals, 1993, 6; 93-100.

[55] Saxena, B., Modi, M., and Modi, V. V. Isolation and characterization of siderophores from Azospirillum lipoferum D-2. J. Gen. Microbiol, 1986, 132; 2219-2224.

[56] Neilands, J. B. Microbial iron compounds, Ann. Rev. Biochem, 1981,$50 ; 715$.

[57] Bevivino, A., Tabacchioni, S., Chiarini, L., Carusi, M. V., Del Gallo, M., V. et. al. Phenotypic comparison between rhizosphere and clinical isolates of Burkholderia cepacia. Microbiol, 1994, 140; 1069-1077.

[58] Shimaila, R., Trevor, C. C., and Bernard R. G. Isolation and characterization of new plant growth-promoting bacterial Endophytes. Appl. Soil Ecology, 2012, 61; 217-224.

[59] Glick, B. R., Penrose, D. M., and Li, J. A model for the lowering of plant ethylene concentrations by plant growthpromoting bacteria. J. Theor. Biol, 1998, 190; 63-68.

[60] Esashi, Y. Ethylene and seed germination. In: The plant hormone ethylene (eds.) A. K. Matoo and J. C. Suttle, $C R C$ press, Boca Raton, FL, 1991, pp. 133-157.

[61] Abdul, L. K., Boshra, A. H., Ali, E., Sajid Ali, Khadija, Al. et al. Indole acetic acid and ACC deaminase fromendophytic bacteria improves the growth of Solanum lycopersicum. Electr. J. Biotechnol, 2016, 21; 58-64. 